\title{
DECISÕES DA JUSTIÇA DO TRABALHO SOBRE AS DEMANDAS NO CAMPO DA ENFERMAGEM
}

Urbanir Santana Rodrigues ${ }^{1}$

Eder Pereira Rodrigues ${ }^{1}$

Paulo Eduardo Santos Santana ${ }^{1}$

\section{Sinara Vera}

Jamille Sampaio Berhends ${ }^{1}$

Tatiane Araújo dos Santos ${ }^{2}$

Ariane Cedraz Moraes ${ }^{3}$ https://orcid.org/0000-0003-0614-9183

https://orcid.org/0000-0002-5972-2871

https://orcid.org/0000-0001-8848-4326

https://orcid.org/0000-0001-5263-0301

https://orcid.org/0000-0002-5315-7349

https://orcid.org/0000-0003-0747-0649

https://orcid.org/0000-0001-9445-4596

Objetivo: analisar as decisões do judiciário trabalhista relacionado às demandas apresentadas pelas trabalhadoras da enfermagem. Método: pesquisa qualitativa que utilizou o método documental. Para análise dos dados foi utilizada metodologia da análise das decisões. Resultados: foram analisadas 22 sentenças e encontradas as seguintes tipologias de precarização: Vulnerabilidades das formas de inserção e no trabalho; Intensificação do trabalho; Insegurança e saúde no trabalho; e Condenação e descarte do direito do trabalho. Conclusão: A análise das sentenças revela que a precarização do trabalho está difundida no campo da enfermagem. Contudo, mediante o cenário de trabalho precarizado, considera-se ainda baixo o quantitativo de trabalhadoras que recorrem à Justiça do Trabalho, o que indica falta de conhecimento sobre direitos trabalhistas ou medo em recorrer a estes.

Descritores: Enfermagem; Legislação Trabalhista; Recursos Humanos de Enfermagem; Profissionais de Enfermagem.

\section{LABOR COURT DECISIONS ON THE NURSING CATEGORY}

Objective: To analyze the decisions of the labor judiciary related to the demands presented by nursing workers. Method: qualitative research that used the documentary method. For data analysis, the decision analysis methodology was used. Results: 22 sentences were analyzed. The types of precariousness found were Vulnerabilities of Forms of Insertion and Work, Intensification of Work, Insecurity and Health at Work, and Condemnation and Dismissal of Labor Law. Conclusion: The analysis of sentences reveals that the precariousness of work is widespread in the nursing field. However, due to the precarious work scenario, the number of female workers who resort to the Labor Court is still low, which indicates lack of knowledge about labor rights or fear of resorting to them.

Descriptors: Nursing; Legislation, Labor; Nursing Staff; Nurse Practitioners.

\section{DECISIONES JUDICIALES LABORALES EN LA CATEGORÍA DE ENFERMERÍA}

Objetivo: analizar las decisiones del poder judicial laboral relacionadas con las demandas presentadas por los trabajadores de enfermería. Metodo: investigación cualitativa que utilizó el método documental. Para el análisis de datos, se utilizó la metodología de análisis de decisión. Resultados: se analizaron 22 oraciones. Los tipos de precariedad encontrados fueron Vulnerabilidades de las formas de inserción y trabajo, intensificación del trabajo, inseguridad y salud en el trabajo, y condena y despido de la legislación laboral. Resultados: Las oraciones revelan que los trabajadores se ven afectados por el trabajo precario a través de vínculos precarios, violencia en el trabajo, flexibilidad, extensión e intensidad del viaje, acumulación de funciones, exposición en entornos poco saludables. Conclusión: el análisis de oraciones revela que la precariedad del trabajo está muy extendida en el campo de la enfermería. Sin embargo, debido al precario escenario laboral, el número de trabajadoras que recurren al Tribunal de Trabajo sigue siendo bajo, lo que indica falta de conocimiento sobre los derechos laborales o temor a recurrir a ellos.

Descriptores: Enfermería; Legislación laboral; Recursos humanos de enfermería; Profesionales de enfermería.

IUniversidade Estadual do Ceará (UECE),CE

${ }^{2}$ Universidade Estadual Vale do Acaraú, Sobral, CE

${ }^{3}$ Universidade Estadual de Feira de Santana, BA.

Autor correspondente: Maria da Conceição Coelho Brito - Email: marycey@hotmail.com

Recebido 07/10/2019 Aceito 30/03/2020 


\section{INTRODUÇÃO}

O trabalho, sob a perspectiva ontológica, é um ato fundante da vida humana. Contudo, com a ascensão do trabalho assalariado na sociedade capitalista, e com a transformação da força de trabalho em mercadoria, este passa a ser alienado e fetichizado ${ }^{(1)}$. No campo da Enfermagem, no contexto da reestruturação produtiva do trabalho flexibilizado e precarizado, a profissional assalariada apenas detém a força de trabalho, sendo destituída dos meios de produção, do controle sobre o processo de trabalho e do capital (2).

Pontua-se que o Estado é uma instituição que se metamorfoseia de acordo com o momento político-econômico e social vigente "economia livre, estado forte" (3:190), assim, no contexto de financeirização da economia, este assume a gestão dos interesses empresariais que converge para a espoliação da força do trabalho através da flexibilização de jornadas, diminuição de rendimentos, aumento do ritmo e intensidade e o descarte dos direitos trabalhistas, e tais situações provocam a fragilização da trabalhadora e a sua vulnerabilidade social (4).

A justiça trabalhista, enquanto Estado-juiz, ocupa a função intermediadora da relação litigiosa que se impõe entre empregada/trabalho e o capital /empregador(es) e, surge como última instância no enfrentamento para a reparação dos danos morais e patrimoniais decorrentes dos vínculos laborais. Assim, esta instância, embora afetada pelo recuo do papel do Estado na proteção aos direitos trabalhistas, ainda é a que os trabalhadores podem recorrer para a garantia mínima de direitos.

Diante disto, objetivou-se analisar as decisões do judiciário trabalhista relacionado às demandas apresentadas pelas trabalhadoras da enfermagem no Estado da Bahia no ano 2017.

\section{MÉTODO}

\section{Tipo de Estudo}

Estudo de abordagem qualitativa, de natureza exploratória, do tipo documental (5).

\section{Participantes da pesquisa}

Foram pesquisadas todas as sentenças trabalhistas que envolviam profissionais de enfermagem, tendo como critérios de inclusão: sentenças cuja demandante fosse trabalhadora do campo da Enfermagem (enfermeira, técnica ou auxiliar de enfermagem), pedido procedente e sentenças geradas pelos dissídios judiciais trabalhistas proferidas entre janeiro e novembro de 2017. Foram excluídas as sentenças julgadas improcedentes e extintivas ao processo e as que tramitavam em segredo de justiça. Após a aplicação dos critérios de inclusão e exclusão, foram selecionadas 22 sentenças.

\section{Local do Estudo}

O recorte institucional foi o Tribunal Regional do Trabalho 5a Região (TRT5). A escolha foi proveniente da pertinência temática e adequação entre o problema e o campo teórico por ser um órgão recursal no âmbito decisório de discussão jurídica.

\section{Coleta de Dados}

A obtenção das sentenças se deu através do acesso ao site http://www.trt5.jus.br/consulta-processo no banco de dados das Bases Jurídicas e a sua Jurisprudência (Sentenças e decisões monocráticas) com os seguintes descritores: 2017, enfermagem, auxiliar de enfermagem, técnica de enfermagem, enfermeiro e enfermeira.

\section{Procedimentos de Análise de dados}

Utilizou-se a metodologia de análise das decisões ${ }^{(6)}$ a partir de três etapas: na primeira, foi elaborada uma tabela que permitiu copilar, em reprodução fidedigna, os elementos do processo trabalhista e a extração da sentença.

No segundo momento foi realizada a leitura individualizada e seletiva de cada sentença, com a finalidade de verificar como os decisores constroem seus argumentos narrativos relacionados aos méritos dos pedidos; e no terceiro momento foi feita a aproximação dos discursos das sentenças às tipologias de precarização do trabalho ${ }^{(4)}$.

Buscou-se, durante a análise, identificar o sentido da prática decisória a partir da narrativa ${ }^{(6)}$. Em seguida, os sentidos extraídos foram confrontados com referenciais teóricos na área da sociologia do trabalho e da enfermagem.

\section{Aspectos Éticos}

$\mathrm{O}$ estudo respeitou as questões éticas conforme as Diretrizes e Normas Regulamentadoras de Pesquisa em Seres Humanos, descritas na Resolução №510/16(7). Os dados utilizados são de domínio público, portanto, não foi necessária a apreciação por Comitê de Ética em Pesquisa. Apesar disto, o anonimato dos sujeitos foi garantido e citados de acordo com a categoria profissional como por exemplo: enfermeiro (SENFl); técnico de enfermagem (STEl); auxiliar de enfermagem (SAEl).

\section{RESULTADOS}

Tomou-se como referência os indicadores de precarização do trabalho ${ }^{(4)}$. No indicador relacionado a Vulnerabilidades das formas de inserção foram enquadrados pedidos de reconhecimento de vínculo, denunciação da lide, recolhimen- 
to ao INSS. Vulnerabilidade no trabalho refere-se as sentenças com pedidos de dano moral, reversão da dispensa, responsabilidade do empregador. Na tipologia Intensificação do trabalho foram inseridos pedidos relacionados a jornada de trabalho que faziam referência ao acúmulo de funções e a extensão da jornada. Na Tipologia Insegurança e saúde no trabalho foram agregados pedidos relacionados a insalubridade, doença ocupacional, repouso semanal remunerado, intervalos inter e intrajornada e trabalho noturno. Na Tipologia Condenação e descarte do direito do trabalho foram agrupados pedidos referentes ao não cumprimento das leis trabalhistas, como anotação na Carteira de Trabalho e Previdência Social (CTPS).

\section{Tipologia 1: Vulnerabilidades das formas de inserção}

Das 22 sentenças analisadas, 14 tiveram pedidos de reconhecimento de vínculo, e destas 11 foram sentenciadas na modalidade contrato nulo. Isto significa que qualquer pessoa contratada pelo serviço público sem prévio concurso, somente terá direito aos salários pelos dias efetivamente laborados e aos valores referentes ao FGTS e terá o contrato declarado pelo juízo como nulo.

\section{Tipologia 2: Vulnerabilidade no trabalho}

Nesta tipologia congregou sete sentenças, deste total, quatro envolveram enfermeiras, e estão relacionadas situações de violência no trabalho como o assédio moral, gestão pelo medo, constrangimento expressos nos depoimentos pelo relato de situações degradantes, humilhantes, vexatórias que as trabalhadoras são expostas e que afeta a dignidade humana.

Uma característica da alienação da trabalhadora é manifesta pela falta de laços de solidariedade entre a categoria e a desfiliação social. A trabalhadora não se percebe como parte da lógica de um sistema de dominação do capital ou, se entende, não consegue se desvencilhar e acaba por assumir o papel opressor frente aos seus pares.

O poder protestativo do empregador é utilizado para punir as trabalhadoras com a dispensa por justa causa, pois, tal modalidade de dispensa não prevê o pagamento de verbas resilitórias. Nesta modalidade encontramos sete processos trabalhistas.

A dificuldade das trabalhadoras em não saber quem acionar perante o judiciário trabalhista, foi verificado nas sentenças com pedido de julgamento sobre a responsabilidade solidária e subsidiária dos empregadores. Este fato, expõe a institucionalização de um modelo jurídico de organização contratual onde o subordinado não sabe com quem deve negociar.

\section{Tipologia 3: Intensificação do trabalho}

Das 22 sentenças analisadas, todas tiveram pedidos relacionados e categorizados na tipologia intensificação do trabalho, porém nos litígios que foram sentenciados na modalidade de contrato nulo, o pedido não foi acolhido por falta de amparo legal porque nesta modalidade contratual a trabalhadora somente terá direito aos salários pelos dias efetivamente laborados, além dos valores referentes ao Fundo de Garantia por Tempo de Serviço.

O pedido de acúmulo de funções traz evidências claras da precarização pela intensidade da jornada e responsabilização da trabalhadora para executar atividades diversas e alheias a sua formação. Revela também o processo de submissão/alienação da trabalhadora aos comandos do empregador para manter o vínculo laboral.

Prestação de horas extras significam aumento da extensão e da jornada do trabalho, na esfera jurídica o não pagamento durante o curso do contrato laboral é traduzido em prejuízo financeiro para a trabalhadora, pois, as horas extras são integradas a remuneração com reflexos em repouso semanal, 13으 salário, férias acrescidas 1/3 e de FGTS. Em outra análise, o excesso de horas extras traz prejuízos a saúde e segurança no trabalho podendo afetar a qualidade de vida da trabalhadora e com possiveis relações com o absenteísmo, doença ocupacional, estresse e ansiedade.

\section{Tipologia 4: Insegurança e saúde no trabalho}

Oito sentenças proferidas estão relacionadas a situações que envolveram atividades insalubres que expõe as trabalhadoras a agentes nocivos à saúde. Assim, precarização social do trabalho pode provocar o adoecimento das trabalhadoras pelo ambiente de trabalho insalubre que é traduzido nos pedidos relacionados ao pagamento por danos morais e materiais decorrentes do acidente de trabalho e/ou doença ocupacional.

No trabalho em saúde é posto a necessidade específica em manter um padrão de assistência diuturna, porém, a especificidade traz prejuizos a saúde física e mental das trabalhadoras, além de prejuizo financeiro por não receber o pagamento do adicional noturno e seus adicionais no curso do contrato de trabalho.

\section{Tipologia 5: Condenação e descarte do direito do trabalho}

Uma das formas de condenação e descarte do direito trabalhista emerge dos pedidos de anotação na Carteira de Trabalho e Previdência Social, significa que as trabalhadoras estão inseridas no mercado de trabalho na informalidade, portanto, sem proteção social. Nesta tipologia, foram 10 pedidos que envolveram anotação e/ou retificação na carteira de trabalho e previdência social. 
Considerando as sentenças trabalhistas proferidas no âmbito do Tribunal Regional do Trabalho da 5a Região que envolveram profissionais de enfermagem, apresenta-se no Quadro 1, o elenco das tipologias da precarização relacionado aos pedidos interpostos de recurso e a sua respectiva evidencia processual.

Quadro 1 - Evidencia processual Tipologias de Precarização do Trabalho (6).

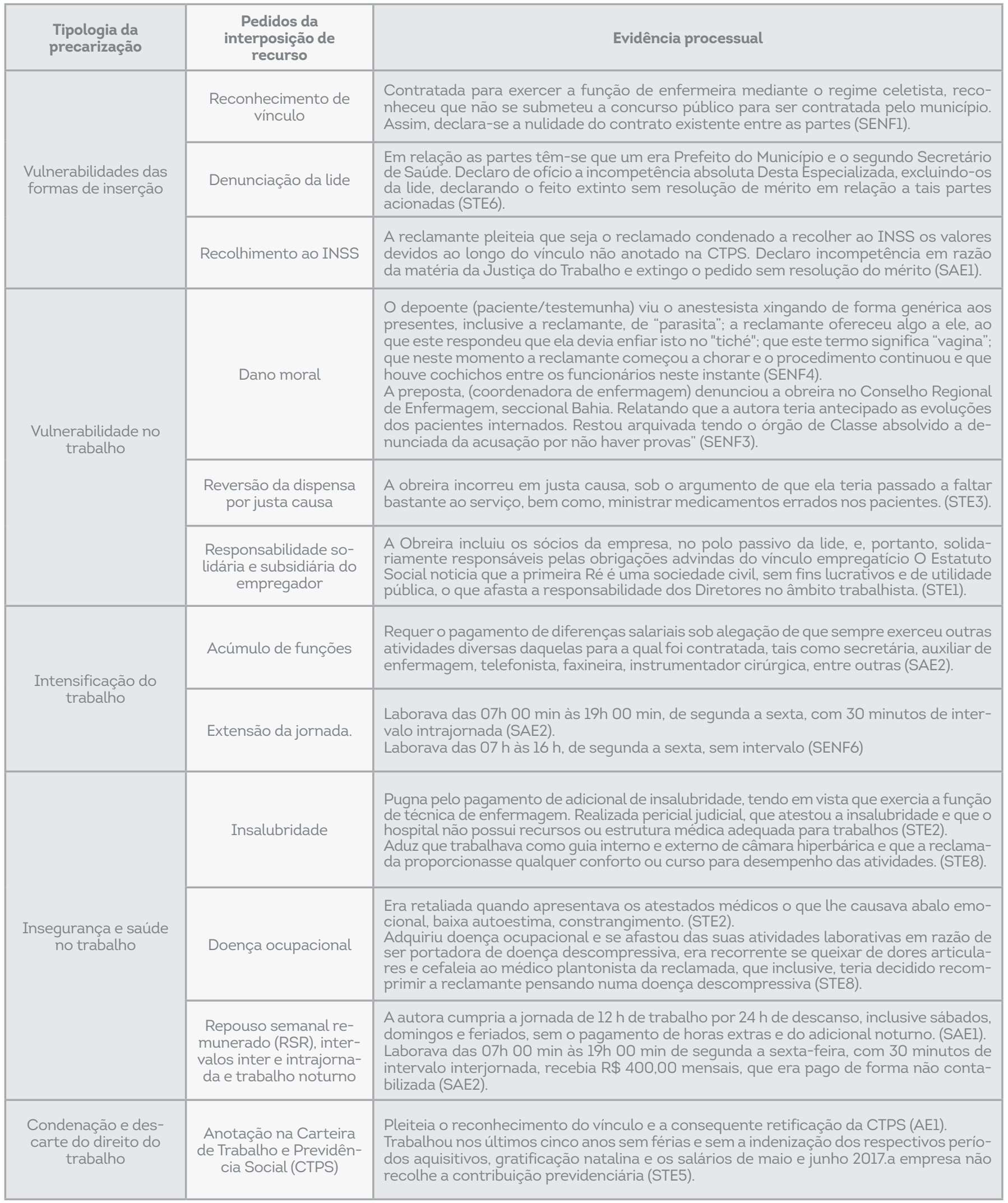




\section{DISCUSSÃO}

As sentenças analisadas neste estudo são provenientes da Justiça do trabalho, que tem competência para processar e julgar ações trabalhistas de contratos regidos pela Consolidação das Leis Trabalhistas, embora, das 22 ações que geraram julgamento, 11 delas foram sentenciadas na modalidade de contrato nulo por fazer pedidos referentes a reconhecimento de vínculo com a administração pública, o que é um dado relevante. $\mathrm{O}$ contrato nulo revela que o Estado, enquanto empregador, tem falhado com relação ao respeito aos princípios fundamentais e basilares que sustentam os direitos sociais, elencados na carta magna ${ }^{(8)}$, onde insere-se o trabalho. Evidencia-se que no contrato nulo, o ônus da ilicitude contratual recai sobre a trabalhadora, que tem apenas o direito de receber o saldo do salário com relação as horas trabalhadas e os valores referentes aos depósitos do Fundo de Garantia por Tempo de Serviço (FGTS).

Ao adotar a doutrina econômica neoliberal, o estado brasileiro reduz gastos públicos e como consequência precariza os serviços públicos e a sua força de trabalho, em especial, as trabalhadoras da enfermagem, que são submetidas a modalidades precárias de contratação, através das novas formas de gestão do trabalho, por meio de organizações sociais, terceirização, fundações privadas de apoio(9).

Ao considerar o contingente de trabalhadoras da enfermagem cerca de 1.800 .000 de um total de 3,5 milhões de trabalhadores de saúde, a situação não é confortável no tocante as relações laborais que envolve a equipe de enfermagem, com destaque a violência no cotidiano das instituições, seja fisica, psicológica, institucional e sexual, assim como as práticas discriminatórias em razão das relações de gênero e raça. Soma-se a este cenário, a falta de segurança no cotidiano do trabalho que repercute diretamente na qualidade de vida das trabalhadoras (10:71).

Neste sentido, põe-se em debate como o neoliberalismo e a financeirização da economia contaminou o sistema estatal, a ponto de que o Estado que elabora as leis, fiscaliza a aplicação das normas e julga atos ilícitos, também é o mesmo Estado que funciona como gestor dos interesses do capital e participa ativamente dos processos de flexibilização e precarização das relações de trabalho.

Adiciona-se que nos casos em que foram sentenciados o contrato nulo, o gestor público não responde pela ilicitude do ato contratual porque a Justiça do Trabalho não detém competência para compor a demanda por se tratar de uma relação de natureza jurídico administrativa.

Apesar da importância do recolhimento previdenciário, muitas empresas descumprem a legislação e as trabalhadoras só descobrem o ilícito no momento em que precisa acessar o Instituto Nacional do Seguro Nacional (INSS). Os pedidos rela- cionados ao recolhimento previdenciário não são julgados porque o judiciário trabalhista não tem competência para julgar a matéria.

Uma das maneiras utilizadas pelo empregador para dissimular o dano provocado no ambiente do trabalho e realizar a gestão pelo medo foi o rompimento do contrato de trabalho através da despedida por justa causa, pois tal modalidade de dispensa não prevê o pagamento de verbas resilitórias. Neste caso, a trabalhadora além de sofrer o dano físico e/ou mental em decorrência do labor, tem acrescido ao sofrimento o prejuízo financeiro por não receber as verbas em decorrência do tipo da desídia.

Para reaver o prejuizo pecuniário, as trabalhadoras recorrem perante o TRT5 para pedir a reversão da dispensa com justa causa, que quando concedidos passam a ter o direito ao 13 salário, férias vencidas e proporcionais, aviso prévio, saldo de salário, multa de 40\% do Fundo de Garantia por Tempo de Serviço (FGTS) e seguro-desemprego.

No Brasil, emerge o discurso midiático e político imposto e, às vezes, banalizado, de que qualquer emprego é melhor do que nenhum ou que é melhor ter emprego que direitos trabalhistas. Esta condição, leva as trabalhadoras a consentir forçosamente o trabalho precário frente a permanente ameaça do desemprego, e mais, a trabalhadora passa a ter uma relação de desenraizamento de classe e se traveste da dominação para oprimir as demais classes que the são subordinadas dentro de um processo de alienação imposta pelo sistema capitalista. Compreender o trabalho alienado permite-nos entrever três grandes rupturas fundamentais para a vida e a saúde: a ruptura nas relações dos homens com a natureza, a ruptura dos laços dos homens entre si e, também, do homem consigo mesmo ${ }^{(11: 34)}$.

Nota-se que a saúde e a segurança no trabalho são dimensões que necessitam de atenção no trabalho em saúde, pois, a inserção do trabalhador em ambientes insalubres, a exposição a horas de trabalho ininterruptas sem horário ou sem infraestrutura adequada para o descanso, a extensão, a intensificação e aumento de carga das jornadas de trabalho são fatores que contribuem para o adoecimento físico e mental das trabalhadoras e que nem sempre é possivel comprovar na seara trabalhista o nexo de causalidade entre a doença e as atividades desempenhadas ${ }^{(11,12.13) .}$

Traz-se que a precarização não atinge somente as trabalhadoras com vínculos fragilizados, como também, as que possuem vínculos estáveis com contrato por tempo indeterminado, por isto, é necessário a participação da classe através de ações coletivas para fortalecer e qualificar as entidades representativas da profissão.

\section{Limitações do estudo}

É importante assinalar, que na totalidade de trabalhadoras 
da enfermagem que tiveram prejuízos em decorrência do contrato de trabalho, nem todas ingressam ou tem acesso em sede de recurso ao judiciário trabalhista porque precisa constituir advogado, assim, esse estudo também guarda limites quanto a generalização dos resultados para a população pesquisada (discordo dessa frase, é representativo, em pouca quantidade, mas representa muito bem. Sugiro que fique só até população pesquisada).

\section{Contribuições para a prática}

A contribuição deste estudo está inserida no campo do trabalho na enfermagem, os seus resultados poderão servir de informação e despertar as trabalhadoras sobre o resultado de ações trabalhistas com relação ao alarmante crescimento da precariedade no trabalho e como os vínculos são cada vez mais flexibilizados para atender a uma lógica mercadológica. Para além, disto, fica a provocação para que os órgãos de fiscalização da enfermagem e do trabalho, dentro de suas atribuições, aumentem a sensibilidade para fiscalizar e intervir nas condições e a forma de inserção das trabalhadoras da enfermagem nos diversos campos da atividade profissional.

\section{CONSIDERAÇÕES FINAIS}

Mediante o cenário de trabalho precarizado, considera-se baixa a quantidade de denúncias encaminhadas à Justiça do
Trabalho, o que pode revelar o desconhecimento por parte das trabalhadoras do campo da enfermagem sobre seus direitos ou o medo de recorrer à Justiça ou a impossibilidade financeira de recorrer, dado que isto demanda a interposição de um(a) advogado(a) em processos que envolvem recurso.

Das tipologias analisadas, destaca-se a vulnerabilidade das formas de inserção, pois trabalhadoras aceitaram um contrato de trabalho nulo no qual o Estado, embora seja o contratante, não é responsabilizado pelo dano. As demais tipologias revelam que a gestão pelo medo e o assédio dissemina-se de diversas formas no campo da enfermagem, sendo a demissão por justa causa a principal forma punitiva feita pelos empregadores. Conclui-se que a precarização do trabalho é uma realidade para o campo da Enfermagem e que suas repercussões jurídicas estão relacionadas de forma estrita com os processos de vulnerabilidade que são expostas as trabalhadoras, ocasionando danos nos processos de saúde e segurança no ambiente do trabalho.

\section{CONTRIBUIÇÃO DOS AUTORES:}

Concepção e desenho, análise e interpretação dos dados, redação do artigo: Urbanir Santana Rodrigues, Paulo Eduardo Santos Santana, Eder Pereira Rodrigues. Revisão crítica, revisão final: Tatiane Araújo dos Santos, Sinara Vera, Jamille Sampaio Berhends, Ariane Cedraz Moraes.

\section{REFERÊNCIAS}

1.Antunes R. Século XXI: nova era da precarização estrutural do trabalho. In: Infoproletários: degradação real do trabalho virtual. São Paulo: Boitempo: 2009. p. 231-8.

2. Melo CMM, Florentino TC. Mascarenhas NB, Macedo KS, Silva MC, Mascarenhas SN. Autonomia profissional da enfermeira: algumas reflexões. Esc Anna Nery - Rev Enferm [Internet]. 2016:20. Disponivel em: http://www.scielo.br/scielo.php?script=sci_arttextEpid=S1414-814520160004006018nrm=iso

3. Dardot P. Laval C. Comum: ensaio sobre a revolução no século XXI. la ed. Echalar M de T, editor. São Paulo: Boitempo: 2017. 534 p.

4. Druck G. Trabalho, precarização e resistências: novos e velhos desafios? Cad CRH [Internet]. 2011:24:37-57. Disponivel em: http://www.scielo.br/scielo.php?script=sci_arttextEpid $=$ S0103-497920110004000048nrm=iso

5. Poupart J, Deslauriers J-P, Groulx L-H, Laperriere A, Mayer R, Pires A. A pesquisa qualitativa: enfoques epistemológicos e metodológicos. In: A pesquisa qualitativa: enfoques epistemológicos e metodológicos. 2014. p. 464.

6. Freitas R, Lima TM. Metodologia de análise de decisões. Univ Jus. 2011;2.

7. Ministério da Saúde (BR).Secretaria de Atenção à Saúde. Departamento de Atenção Básica. Resolução n. 510, de 7 de abril de 2016 . Dispõe sobre as normas aplicáveis a pesquisas em Ciências Humanas e Sociais cujos procedimentos metodológicos envolvam a utilização de dados diretamente obtidos com os participantes ou de informações identificáveis [Internet]. Diário da República 2016 p. 3. Disponivel em: http://bvsms.saude.gov.br/bvs/saudelegis/cns/2016/res0510_07_04_2016.html

8. Brasil. Constituição da República Federativa do Brasil [recurso eletrônico]. -- Brasilia : Supremo Tribunal Federal, Secretaria de Documentação [Internet]. 1988 [cited 2020 Mar 24]. 518 p. Disponivel em: http://www.stf.jus.br/portal/constituicao/constituicao.asp

9. Araújo-dos-Santos T, Silva-Santos H, Silva MN. Coelho ACC, Pires CG S, Melo CMM. Precarização do trabalho de enfermeiras, técnicas e auxiliares de Enfermagem nos hospitais públicos. Rev da Esc Enferm da USP [Internet]. 2018;52. Disponivel em: http://www.scielo.br/scielo.php?script=sci_arttextEpid=S0080-623420180001004898nrm=iso

10. Machado MH, Santos MR, Oliveira E, Wermelinger M, Vieira M, Lemos W, et al. Condições de Trabalho da Enfermagem. Enferm em Foco [Internet]. 2016;7:63. Disponivel em: http:// revista.cofen.gov.br/index.php/enfermagem/article/view/695

11. Franco T. Alienação do trabalho: despertencimento social e desrenraizamento em relação à natureza. Cad CRH [Internet]. 2011:24:171-91. Disponivel em: http://www.scielo.br/ scielo.php?script=sci_arttext\&pid=\$0103-497920110004000128nrm=iso

12. Fernandes MA, Soares LMD, Silva JS. Transtornos mentais associados ao trabalho em profissionais de enfermagem: uma revisão integrativa brasileira. Rev Bras Med do Trab [Internet]. 2018;16:218-24. Disponivel em: http://www.rbmt.org.br/details/318/pt-BR/transtornos-mentais-associados-ao-trabalho-em-profissionais-de-enfermagem--uma-revisao-integrativa-brasileira

13. Rodrigues EP, Rodrigues US, Oliveira L de MM, Laudano RCS, Nascimento Sobrinho CL. Prevalência de transtornos mentais comuns em trabalhadores de enfermagem em um hospital da Bahia. Rev Bras Enferm [Internet]. 2014;67:296-301. Disponivel em: http://www.scielo.br/scielo.php?script=sci_arttext\&pid=S0034-71672014000200296\&lng=en 